\title{
Two Somatic Biallelic Lesions Within and Near SMAD4 in a Human Breast Cancer Cell Line
}

\author{
John Jakob, ${ }^{1,2,3}$ Satoru Nagase, ${ }^{4}$ Adi Gazdar, ${ }^{5}$ Minchen Chien, ${ }^{6}$ Irina Morozova, ${ }^{6}$ James J. Russo, ${ }^{6}$ \\ Subhadra V. Nandula, ${ }^{7}$ Vundavalli V. V. S. Murty, ${ }^{7}$ Chi-Ming Li, ${ }^{1,2,7}$ Benjamin Tycko, ${ }^{1,2,7}$ and Ramon Parsons ${ }^{1,2,7,8 *}$ \\ IInstitute for Cancer Genetics, Columbia University, New York, New York \\ ${ }^{2}$ Herbert Irving Comprehensive Cancer Center, Columbia University, New York, New York \\ ${ }^{3}$ Integrated Program in Cellular, Molecular, and Biophysical Studies, Columbia University, New York, New York \\ ${ }^{4}$ Division of Obstetrics and Gynecology, Hachinohe City Hospital, Hachinohe, Aomori, Japan \\ ${ }^{5}$ Human Center for Therapeutic Oncology Research, University of Texas Southwestern Medical Center, Dallas, Texas \\ ${ }^{6}$ Columbia Genome Center, Columbia University, New York, New York \\ ${ }^{7}$ Department of Pathology, Columbia University, New York, New York \\ ${ }^{8}$ Department of Medicine, Columbia University, New York, New York
}

Loss of chromosome arm $\mathrm{I} 8 \mathrm{q}$ is a common event in human pancreatic, colon, and breast cancers and is often interpreted as representing loss of one or more tumor-suppressor genes. In this article, we describe two novel biallelic deletions at chromosome band I8q2I.I in a recently characterized human breast cancer cell line, HCC-I428. One lesion deletes a fragment of approximately $300 \mathrm{~kb}$ between SMAD4 and DCC that encodes no known genes. The second lesion is an in-frame SMAD4 deletion (amino acids 49-5I) that affects the level of SMAD4 protein but not the SMAD4 message. This change accelerates 26S proteasome-mediated degradation of both endogenous and exogenous mutant SMAD4. Examination of normal DNA from the same patient demonstrated that both lesions are somatic and associated with loss of both normal alleles. These data support the concept that two independent tumor-suppressor loci exist at chromosome segment I8q2I.I, one at SMAD4 and the other potentially at an enhancer of DCC or an unrelated novel gene. (c) 2005 Wiley-Liss, Inc.

\section{INTRODUCTION}

Breast cancer was responsible for the deaths of an estimated 40,200 women in 2003 just in the United States (Ries et al., 2003). Unfortunately, many of the genetic causes of this devastating disease remain unknown. Cancer geneticists have long labored to discover the tumor suppressors and oncogenes altered in breast carcinoma. One approach to identifying novel tumor suppressors has been to characterize biallelic deletions (also known as homozygous deletions) in the genomes of cancer cell lines and xenografts. This strategy proved indispensable for the positional cloning of tumor- suppressor genes including RB1 (Lee et al., 1987), CDKN2A (Kamb et al., 1994), SMAD4 (Hahn et al., 1996b), and PTEN (Li et al., 1997). With the human genome project now complete, biallelic deletions should prove easier to map and candidate tumor-suppressor genes easier to identify.

Representational difference analysis (RDA) allows an investigator to perform a genomewide, unbiased screen for biallelic deletions (Lisitsyn and Wigler, 1993). RDA, a PCR-based subtractionhybridization technique, was integral to the identification of the biallelic deletions utilized to clone the candidate tumor suppressors PTEN (Li et al., 1997), LRP1B (Liu et al., 2000), and BRCA2 (Schutte et al., 1995).

This study employed RDA in a screen for biallelic deletions in the genome of the recently isolated breast cancer cell line HCC-1428. RDA uncovered one novel biallelic deletion in the HCC-1428 genome, on the 18q21.1 chromosome segment. We were able to demonstrate that the biallelic deletion does not alter the open-reading frames (ORFs) of the SMAD4 or $D C G$ candidate tumor-suppressor genes, also on chromosome segment $18 \mathrm{q} 21.1$. We mapped the extent of the deletion, determined its length as $260-330 \mathrm{kbp}$, and localized it as being between the SMAD4 and DCC loci. Sequence analysis of the SMAD4 gene in the HCG-1428 cell line identified only an allele with a

Supported by: National Institutes of Health; Grant numbers: PO1 CA97403; RO1 CA82783, and RO1 CA99523; Medical Scientist Training Program of the National Institute of General Medical Sciences (to J.J.).

*Correspondence to: Ramon Parsons, Room 302, Institute for Cancer Genetics, Columbia University, Russ Berrie Pavilion, 1150 St. Nicholas Avenue, New York, New York 10032.

E-mail: rep15@columbia.edu

Received 21 May 2004; Accepted 6 October 2004

DOI 10.1002/gcc.20142

Published online 11 January 2005 in

Wiley InterScience (www. interscience.wiley.com). 
novel in-frame and protein destabilizing mutation whose predicted effect was to delete amino acids 49-51 of the MH1 domain. The existence of a second biallelic deletion of approximately 300 kilobase pairs (kbp) between the SMAD4 and $D C C$ genes suggests the potential to select for loss of an additional tumor-suppressor locus resident on chromosome segment 18q21.1.

\section{MATERIALS AND METHODS}

\section{Cell Lines}

Human breast carcinoma cell lines MDA-MB468, MDA-MB-415, MDA-MB-474, MDA-MB-453, MCF7, and T-47D, human colorectal carcinoma cell line SW-480, human glioblastoma cell line U-87, and the African green monkey kidney, SV40-transformed COS-1 cell line were acquired from the American Type Culture Collection (ATCG) (Manassas, VA) and cultured according to the distributor's instructions. Human mammary epithelial cells (HMEG) were purchased from Clonetics (San Diego, CA) and cultured per the distributor's instructions. The Gazdar laboratory isolated breast carcinoma cell lines HCC-1428, HCC-1428 BL, HCC-1937, and HCC-1143; they are now available from the ATCG (Gazdar et al., 1998).

\section{Representational Difference Analysis}

Representational difference analysis (RDA) was performed essentially as described by Lisitsyn and Wigler (1993). Specifically, the HCC-1428 genome served as the "driver genome," or template for the driver; the HCC-1428 BL genome as the "tester genome," or template for the tester. BglII restriction endonuclease (New England Biolabs, Beverly, MA) was employed to construct the driver and the tester. Our RDA methodology did differ from the original protocols in the ratio of driver to tester that was used for subtraction-hybridization. To set up the first-round subtraction-hybridization reaction, driver and tester were mixed in an 80:1 ratio $(40 \mu \mathrm{g}$ driver:500 ng tester). For the second-round subtraction-hybridization, an 800:1 ratio was employed (40 $\mu \mathrm{g}$ driver:50 $\mathrm{ng}$ tester). In the third-round subtraction-hybridization, driver and tester were mixed in a 400,000:1 ratio (40 $\mu \mathrm{g}$ driver:100 pg tester).

\section{Screening Products of Representational Difference Analysis of the HCC-I428 Genome for Deleted Sequences}

RDA products were cloned into the pZeroII vector (Invitrogen, Carlsbad, CA) using the
BamHI site, electroporated into DH10B E. coli. (Invitrogen), and 800 colonies were selected for sequencing. We performed all sequencing in this study on the ABI Prism 377 DNA sequencer (Applied Biosystems, Foster City, CA). In a PCR screen for deleted fragments, the HCC-1428 BL genome was used as the template for a positive control reaction.

\section{Polymerase Chain Reaction}

All polymerase chain reactions (PCR) in this study were performed under the following conditions unless otherwise indicated: $10 \mu \mathrm{L}$ volume with $16.6 \mathrm{mM}(\mathrm{NH})_{2} \mathrm{SO}_{4}, 67 \mathrm{mM}$ Tris-HCl $(\mathrm{pH}$ 8.8), $6.7 \mathrm{mM} \mathrm{MgCl}_{2}, 10 \mathrm{mM}$ 2-mercaptoethanol, $0.25 \mathrm{mM}$ dNTPs, $6 \%$ DMSO, $350 \mathrm{ng}$ of each primer, and 0.5 U of Platinum Taq (GibcoBRL, Carlsbad, CA). PCR reactions were performed on $10 \mathrm{ng}$ of genomic DNA. All PCR reactions were carried out on a Hybaid Omnigene Thermocycler (Thermo Electron Corporation, Waltham, MA). PCR primers used in this study are available on request.

\section{Bacterial Artificial Chromosome Isolation and End Sequencing}

The sequence-tagged site (STS) SHGC-7133 was used to PCR-screen the Human Bacterial Artificial Chromosome Release II Library (Genome Systems, St. Louis, MO). We used a NucleoBond Plasmid Kit (Clontech, Palo Alto, CA) to isolate bacterial artificial chromosomes (BACs) 494J9 and 471M4. SP6 and T7 primers were used to sequence BAC ends.

\section{Sequence-Tagged Site Mapping}

PCR conditions and primers for sequencetagged sites used in this study are available on request as are STS coordinates on the NCBI chromosome 18 contig (accession no. NT_010966.13, October 17, 2003, version). PCR products of novel STSs probe B, 84-2, 494J9-T7, rpS8-like EST, 800-20K, and 494J9-SP6 were sequenced directly in order to confirm their identities. The control PCR fragment was from chromosome 2, NCBI accession number AC012305.7, coordinates 78,32378,502 .

\section{Single-Nucleotide Polymorphism Analysis}

Candidate single-nucleotide polymorphisms (SNPs) in the deleted region were identified with the NCBI dbSNP database and PCR-amplified from the HCC-1428 BL genome. Sequence analysis of candidate SNP PCR products demonstrated 
A)

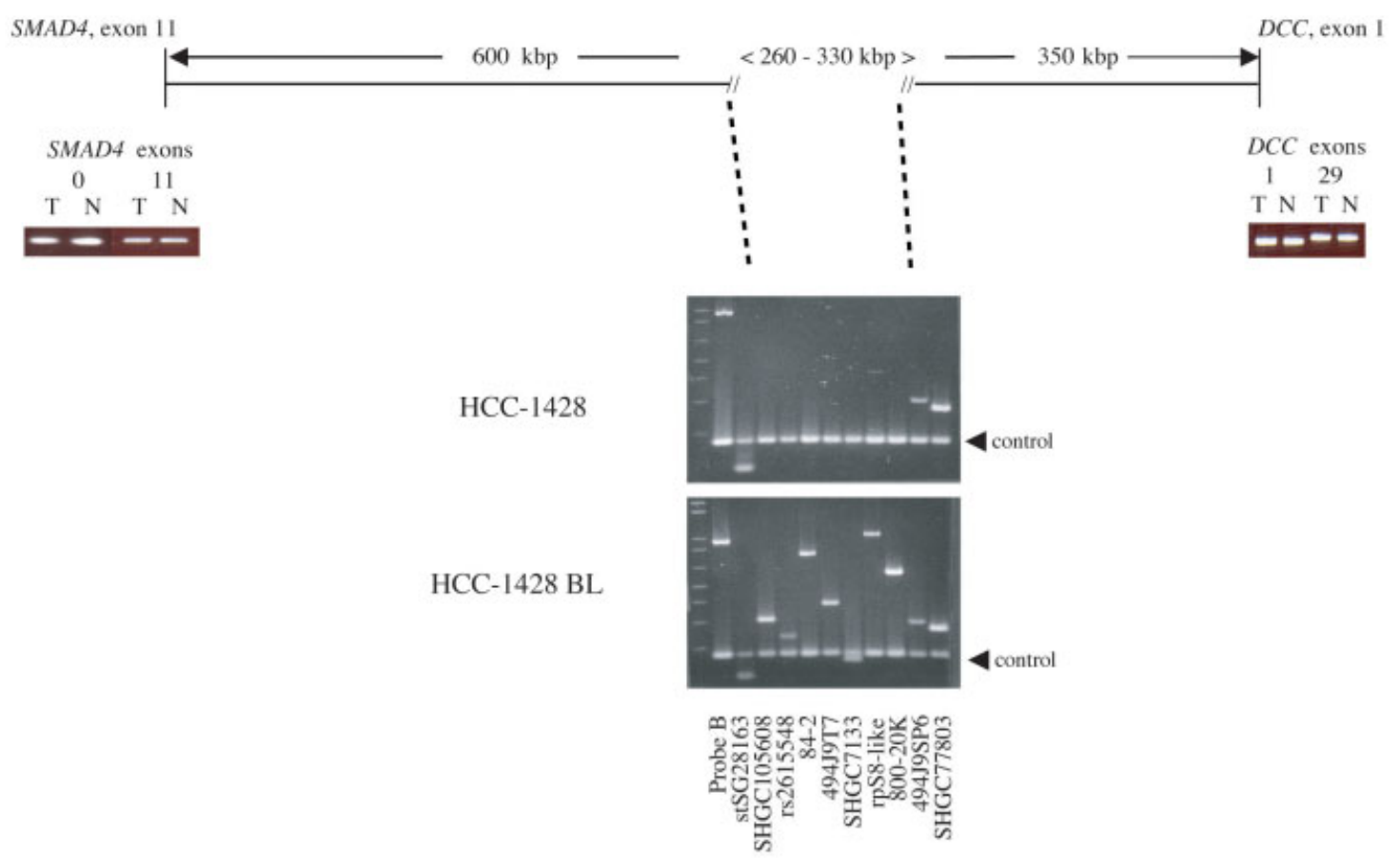

\section{B)}

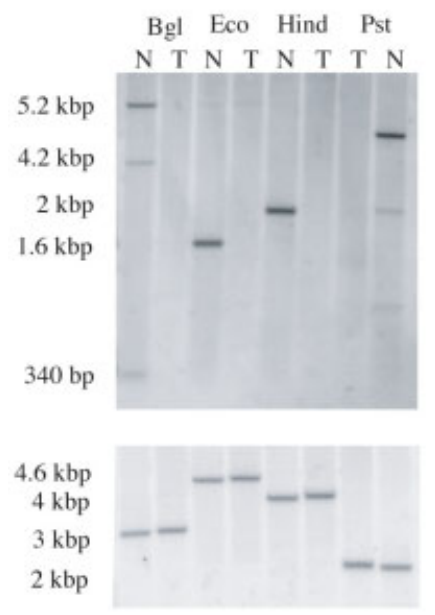

C)

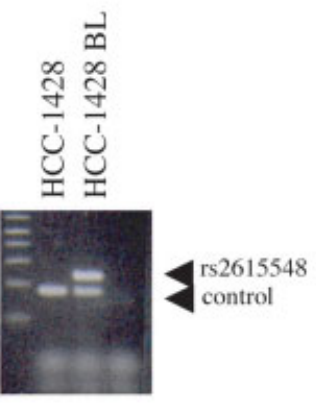

Probe A

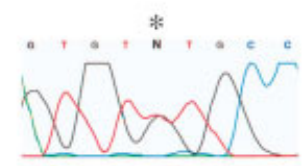

rs2615548 HCC-1428 BL

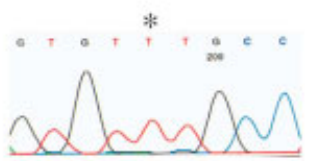

rs 2615548

"T" allele, HCC-1428 BL

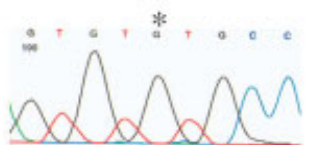

rs2615548

"G" allele, HCC-1428 BI 
that rs2615548 was present in two variants in the HCC-1428 BL genome. An ambiguous nucleotide (peaks at both $\mathrm{G}$ and $\mathrm{T}$ ), referred to as $\mathrm{N}$, was detected at the predicted rs2615548 SNP position. To confirm that both the $\mathrm{G}$ and $\mathrm{T}$ alleles were amplified from the HCC-1428 BL genome, this PCR product was cloned into the pZeroII vector, and individual clones were sequenced. The $G$ and $\mathrm{T}$ alleles were detected with equal frequency. Results were confirmed with a second rs 2615548 SNP PCR amplification from the HCC-1428 BL genome and subsequent product sequencing. The control PCR fragment also was from chromosome 2, NCBI accession \#AC012305.7, coordinates 78,323-78,502.

\section{Southern Blot Analysis}

For Southern blot analysis, restriction-digested DNA was electrophoresed through a $0.8 \%$ agarose gel and transferred to Zeta-Probe GT membranes (Bio-Rad, Hercules, CA). Probes were labeled with ${ }^{32} \mathrm{P}$ dCTP by the random hexamer method (Feinberg and Vogelstein, 1983). Probe hybridization to membrane was carried out overnight at $68^{\circ} \mathrm{C}$ in $10 \mathrm{~mL}$ of ExpressHyb (Clontech); membranes were then washed for $15 \mathrm{~min}$ at $6^{\circ} \mathrm{C}$ in $0.3 \times \mathrm{SSC} / 0.1 \% \mathrm{SDS}$, and the results were visualized with the Storm 840 phosphoimage system (Molecular Dynamics, Sunnyvale, CA). Probe A was derived from the NCBI chromosome 18 contig, accession \#NT_010966.13, coordinates 30,787,107-30,786,164. Probe B also was derived from the NT_010966.13 contig, coordinates 30,682,148-30,681,194. The cytogenetic locations of probes $\mathrm{A}$ and $\mathrm{B}$ relative to $B I D-C H R 18$ are indicated in Figure $1 \mathrm{~A}$. Both probe $\mathrm{A}$ and probe $\mathrm{B}$ were synthesized by PCR and sequenced to confirm their identities.

\section{Northern Blot Analysis}

Total RNA was isolated from the indicated cell lines according to the cesium chloride/guanidium isothiocyanate method (Sambrook et al., 1989). RNA was resolved on a $1 \times$ MOPS gel by electrophoresis and transferred onto a NYTran membrane (Schleicher and Schuell BioScience, GmbH, Dassel, Germany). DNA probes were labeled with ${ }^{32} \mathrm{P}$
dCTP by the random hexamer priming method. Blots were hybridized at $42^{\circ} \mathrm{C}$ in UltraHyb (Ambion, Austin, TX). The membrane was washed in $0.1 \times \mathrm{SSC} / 0.1 \% \mathrm{SDS}$ at $60^{\circ} \mathrm{C}$ and exposed to film at $-70^{\circ} \mathrm{C}$ using intensifying screens. After SMAD4 hybridization and exposure, the membrane was stripped by boiling for $30 \mathrm{sec}$ in $0.1 \times \mathrm{SSC} / 0.1 \%$ SDS before being hybridized with the beta actin probe. The SMAD4 probe was constructed by EcoRI and Pst I restriction digest of the SMAD4FLAG plasmid and isolation of the 300-bp fragment at the $3^{\prime}$ end of the SMAD4 ORF. The beta actin probe was described previously (Wu et al., 1999).

\section{Reverse Transcription Polymerase Chain Reaction}

cDNA was synthesized from $5 \mu \mathrm{g}$ of the whole RNA template with random primers and SuperScript II RNase $\mathrm{H}^{-}$Reverse Transcriptase (GibcoBRL) according to the manufacturer's instructions. Human breast RNA was acquired from Invitrogen, human fetal brain RNA from Stratagene (La Jolla, CA). Professor V. Band, of the Radiation Oncology Department of New England Medical Center, provided RNA from the human mammary epithelial cell cultures $70 \mathrm{~N}$ and $76 \mathrm{~N}$ and the transformed breast cell cultures 70E6 and 76E6 (Wazer et al., 1995). PGR primers hed1R and hed3F amplify a cDNA product spanning exons 24 of the DCC transcript. Cyclophilin A was chosen as a housekeeper control, as a recent report indicated it is present at low copy number in both normal and cancerous breast tissue (Tricarico et al., 2002). Primers CYCA-F1 and CYCA-R1 amplify a cDNA product that includes exons $1-5$. The cyclophilin A and DCG reverse transcription polymerase chain reaction (R'T-PCR) products were sequenced to confirm their identities.

\section{Western Blot Analysis, Immunoprecipitation, and Antibodies}

Protein lysates $(25 \mu \mathrm{g})$ were resolved with $4 \%-$ $20 \%$ Tris-glycine gels (Invitrogen) and transferred onto Immobilin-P membranes (Millipore, Bedford, MA). For immunoprecipitation with M2-FLAG antibody agarose beads (Sigma-Aldrich, St. Louis, $\mathrm{MO})$, the cells were lysed in a buffer containing $20 \mathrm{mM}$ Tris-HCl (pH 7.5), $150 \mathrm{mM} \mathrm{NaCl,} 10 \%$
Figure I. The HCC-1428 genome has a biallelic deletion of 260 $330 \mathrm{kbp}$ between tumor-suppressor genes SMAD4 and DCC. (A) PCR sequence-tagged site (STS) map of the 260-330 kbp BID-CHRI 8 deletion (human chromosome 18 centromere to the left, $18 q$ telomere to the right; control PCR fragment is from chromosome 2; accession no. AC0 I2305.7, coordinates 78,323-78,502; T, HCC-I428; N, HCC-I428 $B L)$. (B) Southern blot analysis confirms BID-CHR/8 deletion. Probe A spans STS 84-2. The location of probe $B$ relative to $B I D-C H R / 8$ is indicated in panel A (Bgl, Bglll; Eco, EcoRI; Hind, HindllI; Pst, Pstl). (C) Sequence analysis demonstrates two alleles of single-nucleotide polymorphism rs26I5548 in HCC-I428 BL genome, both deleted from the HCC-I428 genome. The control PCR fragment is identical to the panel A control. 
glycerol, $1 \%$ triton, $2 \mathrm{mM}$ EDTA protease inhibitor cocktail set I (CalBiochem, San Diego, CA), $1 \mathrm{mM} \mathrm{Na}_{3} \mathrm{VO}_{4}$, and $40 \mathrm{mM} \mathrm{NaF}$. The beads were precipitated, resuspended in Laemmli sample buffer, and subjected to immunoblot analysis. The primary antibodies used in this study were mouse monoclonal:B-8, for Smad4 (Santa Cruz Biotechnology, Santa Cruz, CA); TU02, for tubulin (Santa Cruz Biotechnology); M2-FLAG, for FLAG (Sigma-Aldrich); JL-8, for GFP (Clontech); and Hvin1, for vinculin (Sigma-Aldrich).

\section{Plasmids}

Full-length (normal) SMAD4 and $\Delta(49-51)-$ SMAD4 cDNAs, from MCF7 and HCC-1428 cDNAs, respectively, were cloned into the $\mathrm{C}$ terminal FLAG expression vector pGMVTag4A (NCBI accession no. AF073000; Stratagene). RTPCR was performed with Pfx Platinum Polymerase (Invitrogen) according to the manufacturer's instructions. Thorough sequence analysis of Smad4-FLAG and $\Delta(49-51)-$ Smad4-FLAG confirmed their identities.

\section{Pulse Chase Analysis}

COS-1 cells at $50 \%$ confluence were transfected with either the SMAD4-FLAG or the $\Delta(49-51)$ SMAD4-FLAG plasmids. For transfection, $5 \mu \mathrm{g}$ of plasmid and $60 \mu \mathrm{L}$ of lipofectamine (Invitrogen) per $75 \mathrm{~cm}^{2}$ flask were used; each $75-\mathrm{cm}^{2}$ flask of cells represented a time point in the pulse-chase experiment. Forty-eight hours posttransfection, the cells were placed in L-methionine- and L-cystinefree DMEM and 5\% dialyzed fetal bovine serum with ${ }^{35} \mathrm{~S}$-labeled L-methionine and L-cystine at 180 $\mu \mathrm{Ci} / \mathrm{mL}$ for $2 \mathrm{hr}$ at $37^{\circ} \mathrm{C} / 5 \% \mathrm{CO}_{2}$ (Amersham Biosciences, Piscataway, NJ). Chase with cold L-methionine and L-cystine was carried out for the specified periods. Sequential immunoprecipitation with M2-FLAG antibody agarose beads was performed twice before the labeled protein was resolved on a 4\%-20\% Tris-glycine gel according to standard protocols (Struhl, 2001). After drying, the gels were placed between 6 - $\mu$ m-thick single layers of Standard Mylar(Somar International Inc., Sparks, NV), exposed for 5-7 days to the LE storage phosphoimage screen (Amersham Biosciences), and the images processed with the Storm 840 system.

\section{Proteasome Inhibitors}

MG-132 (Z-Leu-Leu-Leu-al) was purchased from Sigma-Aldrich. PS-341 (also known as Bortezomib or Velcade) was a gift of Millennium Pharmaceuticals (Cambridge, MA).

\section{Fluorescence In Situ Hybridization}

Fluorescence in situ hybridization (FISH) was performed by standard methods on metaphase cells prepared from the HCC-1428 cell line. A Spectrum Orange-labeled CEP18 centromeric probe and a SpectrumGreen-labeled chromosome 18 paint probe (both obtained from Vysis, Downers Grove, IL) was used in dual-color FISH. Fluorescence signals were captured after a DAPI counterstain on an Applied Imaging Cytovision Imaging system attached to a Nikon Eclipse 600 microscope.

\section{RESULTS}

\section{Representational Difference Analysis Identified a Novel Biallelic Deletion in the HCC-I428 Genome}

The HCC-1428 RDA library provided 740 readable sequences, 62 of which $(8.4 \%)$ represented sequences present in the HCC-1428 BL genome but absent in the HCC-1428 genome (Table 1). One sequence, 84-2, perfectly matched NCBI accession number AC027216.6, at chromosome band 18q2.1, coordinates 49,580-50,359. Southern blot analysis confirmed deletion of this sequence from the HCC-1428 genome (Fig. 1B).

To determine whether this novel deletion represented the somatic loss of two alleles, sequence analysis of candidate SNPs was performed. Sequence analysis of the HCC-1428 BL (paired normal) PCR products of candidate SNP rs2615548 revealed two alleles, $G$ and T. Candidate SNP rs2615548 did not amplify from the HCC-1428 genome (Fig. 1C). The deleted locus was named biallelic deletion of chromosome 18 , BID-CHR18.

\section{BID-CHRI 8 Spans 260-330 Kilobase Pairs and Is Between Candidate Tumor-Suppressor Genes SMAD4 and DCC}

BLAST searches of the NCBI HTGS and NR databases mapped BID-CHR18 to NCBI accession number AC027216.6, at chromosome band 18q21.1. PCR radiation hybrid mapping of the 842 fragment with the Stanford G3 Human/Hamster RH Panel also localized the deletion to $18 \mathrm{q} 21.1$, within $5 \mathrm{cM}$, or about $100 \mathrm{kbp}$, of STS SHGC7133. A physical map of the deletion was constructed with publicly available STSs and the NCBI HTGS and NR databases. The centromeric end of the deletion was determined to within 40 kbp. SHGC-105608, at AC027216.6, coordinates 109,631-109,933, did not PCR-amplify from the HCC-1428 genome, whereas stSG28163, at 
TABLE I. Results of Representational Difference Analysis (RDA) of Genome of Breast Cancer Cell Line HCC-I428

\begin{tabular}{lc}
$\begin{array}{l}\text { Accession No. } \\
\text { Coordinates (Gene) }\end{array}$ & $\begin{array}{c}\text { Fragments Detected } \\
\text { by RDA Process } \\
\text { (\% of total) }\end{array}$ \\
\hline AFI52363, I64,476-6I4,775 (FRA3B) & $15(2 \%)$ \\
HS4B958RAJ, 87,072-87,423 (EBV) & $18(2.4 \%)$ \\
AC0272 I6.6, 49,960-50,298 (\#84) & $29(3.9 \%)$ \\
All fragments not present in & $62(8.4 \%)$ \\
$\quad$ the HCC- I428 genome & $740(100 \%)$ \\
\hline \begin{tabular}{l} 
Fragments detected by RDA process \\
\hline
\end{tabular}
\end{tabular}

AC027216.6, coordinates 150,505-150,627, did amplify from the HCG-1428 genome (Fig. 1A).

To map the telomeric extent of the deletion, we performed a PCR screen of a human BAC library for SHGC-7133 isolated BAC 494J9. STS 494J9 SP6, present in the HCC-1428 genome, maps to NCBI accession number AC105032.4, coordinates 22,666-22,965. Overlap of AC105032.4 with NCBI accession number AC080051.6 and a novel STS we generated from the latter, $800-20 \mathrm{~K}$, localized the telomeric extent of BID-CHR18 to $27 \mathrm{kbp}$ between 800-20 K and 494J9SP6 (Fig. 1A). Ultimately, sequence information from NCBI accession numbers AC027216.6, AC022701.6, and AC080051.6, as well as from the UCSC human genome server, July 2003 freeze, allowed us to conclude that BID-CHR18 is $260-330 \mathrm{kbp}$ in size and between candidate tumor suppressors SMAD4 and $D C G$ (Fig. 1A).

We performed a PCR screen of STSs SHGC7133 and $84-2$ on a panel of 40 breast cancer cell line genomes and 40 breast cancer xenograft genomes. Both SHGC-7133 and the 84-2 fragment amplified in all 80 genomes (results not shown).

\section{Bioinformatic Analysis of BID-CHRI8 Revealed No Known Genes}

BID-CHR18 is unremarkable, save for its paucity of known coding sequence. No known genes or spliced expressed sequence tags (ESTs) are contained in BID-CHR18 as assessed by BLAST searches and analysis with the UCSC human genome browser, April 2003 freeze. BID-CHR18 has no known microRNA genes. We performed Paracel BLAST (Paracel Inc., Pasadena, CA) of BID-CHR18 (using accession nos. AC027216.6, AC022701.6, and AC080051.6) versus 1,138 candidate chromosome 18 exons found by trap analysis (Chen et al., 2003). This approach identified three putative exons, NCBI accession nos. BH608849, BH608723, and BH608687, within BID-CHR18.
However, repeated exon connection RT-PGR reactions on human fetal brain, fetal testis, and breast cDNA templates failed to amplify the spliced transcripts containing these sequences.

BID-CHR 18 contains an unexceptional number of human-mouse orthologous regions. BID-CHR18 (April 2003 UCSC freeze) was compared to the corresponding mouse region (February 2003 UCSC freeze) with the VISTA 2.0 browser. This approach revealed 51 regions of $50 \mathrm{bp}$ or more that had more than $90 \%$ nucleotide identity between human and mouse. All human-mouse hits were checked for synteny and best possible matches. The similar regions covered a combined $4,998 \mathrm{bp}$, or $1.5 \%$ of the maximum possible ( $\sim 330 \mathrm{kbp})$ BID-CHR18. This is consistent with the findings of the Mouse Genome Sequencing Consortium, which concluded that roughly $2.3 \%$ of the human genome is conserved in the mouse in small segments $(\leq 50 \mathrm{bp})$ that are not coding sequences, $5^{\prime}$ UTRs, $3^{\prime}$ UTRs, or repeats (Waterston et al., 2002). There is synteny of the SMAD4-(BID-CHR18)-DCC arrangement between humans and mice. However, this also was expected because $90 \%$ of the human genome shows synteny with the mouse genome (Waterston et al., 2002).

RepeatMasker analysis of the BID-CHR18 demonstrated that $49 \%$ of the deleted sequence represents interspersed repeats. Specifically, BIDCHR18 consists of $7.5 \%$ SINEs, $27.3 \%$ LINEs, $11.3 \%$ LTR elements, and $3.4 \%$ DNA transposon elements. These proportions are very similar to the average number of human genome-wide interspersed repeats: $44 \%$ combined, $13 \%$ SINE sequences, $20 \%$ LINE sequences, $8 \%$ LTR sequences, and 3\% DNA transposon elements (Lander et al., 2001).

\section{BID-CHRI 8 Is in the $5^{\prime}$ Extension Intergenic Region of DCC}

The BID-CHR18 deletion does not extend into the $D C G$ ORF of the HCC-1428 genome (Fig. 1A). At $\sim 300 \mathrm{kbp}$, the apparently gene-barren BIDCHR18 constitutes part of a large intergenic region upstream of $D C C$. The $350 \mathrm{kbp}$ between the first exon of $D C G$ and $B I D-C H R 18$ lack any known genes or spliced ESTs, meaning that $D C C$ has a $5^{\prime}$ extension intergenic region of at least 700 kbp (distance from the $5^{\prime}$ end to the nearest upstream gene). In contrast, a recent analysis of $5^{\prime}$ extension intergenic regions found medians of 46 and $18 \mathrm{kbp}$ for chromosomes 21 and 22, respectively (Chen et al., 2002).

RT-PCR analysis detected $D C G$ transcripts in human fetal brain and adult breast cDNAs; 
sequence analysis of these PGR products confirmed their identity. The $D C G$ cDNA did not amplify from the HCC-1428 cDNA, nor did it amplify from nontransformed, cultured breast epithelial cells HMEC, 70N, and 76N cDNAs, possibly because of dedifferentiation of breast cells in culture (Fig. 2F). Western blot analysis of the DCC protein failed to detect it in the HCC-1428 or other breast cancer cell lines or cultures (results not shown).

\section{The HCC-I 428 I 8q2 I. I Band Also Contains a Biallelic Deletion at SMAD4}

Northern blot analysis demonstrated that the SMAD4 message was not disrupted in the HCC1428 cell line (Fig. 2D). However, sequence analysis of SMAD4 in the HCC-1428 genome revealed only an allele with a 9-bp deletion of exon 1 ablating amino acids 49, 50, and 51 (Fig. 2C). Sequence analysis of the entire ORF, $5^{\prime}$ UTR, and $3^{\prime}$ UTR of the HCC-1428 SMAD4 gene uncovered no additional mutations. The mutation was confirmed in the SMAD4 transcript of the HCC-1428 cell line. The normal SMAD4 exon 1 sequence did not amplify from the HCC-1428 genome, indicating that both normal copies of SMAD4 exon 1 had been lost from the HCC-1428 genome (Fig. 2B). In addition, Western blot analysis demonstrated that endogenous mutant SMAD4 protein was almost undetectable in the HCC-1428 proteome (Fig. 2E). This SMAD4 mutation was named, in line with the guidelines of the HUGO Mutation Database Initiative in genomic DNA, cDNA, and protein contexts, g.144_152del, c.144_152del, and p.Glu49_Lys51del, respectively (den Dunnen and Antonarakis, 2000), referred to henceforth as $\Delta(49-51)$-SMAD4.

\section{$\Delta(49-5$ I) Mutation Enhanced SMAD4 Protein Degradation}

Western blot analysis demonstrated that endogenous $\Delta(49-51)-S M A D 4$ protein was almost undetectable in the HCC-1428 proteome (Fig. 2E). To explore the effect of $\Delta(49-51)$ on the steady-state level of SMAD4 protein, we transfected normal SMAD4-FLAG and $\Delta(49-51)-S M A D 4-F L A G$ constructs into COS-1 cells. Immunoprecipitation was needed to detect the mutant SMAD4-FLAG protein, which was found to have a much lower steady-state level than did normal SMAD4-FLAG (Fig. 3A). To determine whether $\Delta(49-51)$ decreased SMAD4 protein synthesis or stability, we transfected normal SMAD4-FLAG and $\Delta(49-51)$ SMAD4-FLAG plasmids into COS-1 cells and performed pulse chase analysis. A 2-hr pulse labels similar amounts of normal and mutant protein. In this assay, labeled SMAD4-FLAG was stable for $18 \mathrm{hr}$, but $\Delta(49-51)$-SMAD4-FLAG had a half-life of less than 4 hr (Fig. 3B).

\section{Proteasome Inhibition Increased the Level of Exogenous and Endogenous $\Delta(49-5 \mathrm{I})-S M A D 4$ in HCC- 1428 Cells}

To characterize the mechanism of the enhanced degradation of $\Delta(49-51)$, COS-1 cells transfected with normal SMAD4-FLAG and $\Delta(49-51)-$ SMAD4-FLAG were incubated with MG-132, a $26 \mathrm{~S}$ proteasome inhibitor. A concentration of $50 \mu \mathrm{M}$ was needed to observe even modest stabilization at $4 \mathrm{hr}$ (Fig. 3A). At this concentration, MG132 is toxic to COS-1 cells, leading to a dramatic decrease in normal SMAD4-FLAG after more than $4 \mathrm{hr}$ (not shown). However, 24-hr treatment of HCC-1428 cells with the proteasome inhibitors MG-132 $(10 \mu \mathrm{M})$ or PS-341 $(100 \mathrm{nM})$ caused a dramatic increase in the level of endogenous $\Delta$ (49-51)-SMAD4 protein (Fig. 3C).

\section{Chromosome Paint Analysis Demonstrated an Unbalanced Translocation of Chromosome Arm I8q in HCC-I 428 Cells}

FISH, using orange chromosome 18 centromeric and green chromosome 18 paint probes, was performed on HCC-1428 to determine the structure of chromosome 18 . The analysis of HCC-1428 cells identified one intact chromosome 18 in all cells and an unbalanced chromosome 18 translocation, with the proximal half of $18 \mathrm{q}$ detected, making a net loss of one copy of distal 18q21 material (Fig. 4). Therefore, only one allele of chromosome 18 is present in the SMAD4-BID-CHR18-DCC interval.

\section{DISCUSSION}

Frequent loss of specific chromosome arms often is interpreted as representing loss of canonical, genetic two-hit tumor-suppressor genes. Potential candidate tumor-suppressor genes for human chromosome arm 18q include SMAD4 and $D C C$. However, neither SMAD4 nor DCC has a frequency of mutation of both alleles approaching that of the observed LOH and CGH in breast cancer. The rate of loss of both SMAD4 alleles, as judged by immunohistochemistry, is $2 \%$ in sporadic breast cancer (Xie et al., 2002). Only one case of mutation of both SMAD4 alleles has been reported previously in breast cancer (Schutte et al., 1996). A two-hit lesion of $D C C$ has never been documented in breast cancer. 
A)

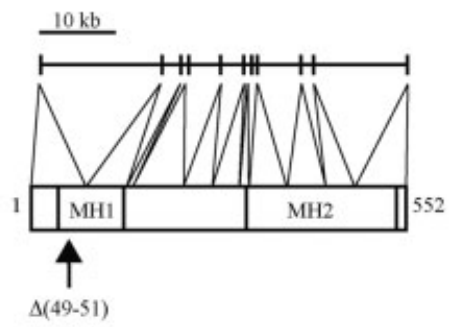

C)

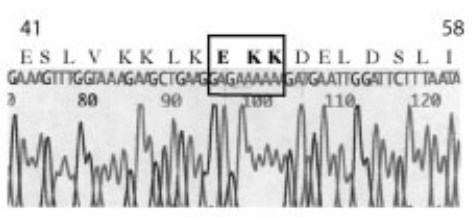

HCC-1428 BL

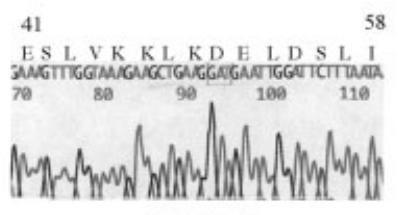

HCC- 1428
B)

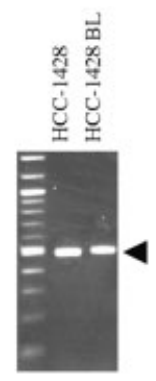

D)

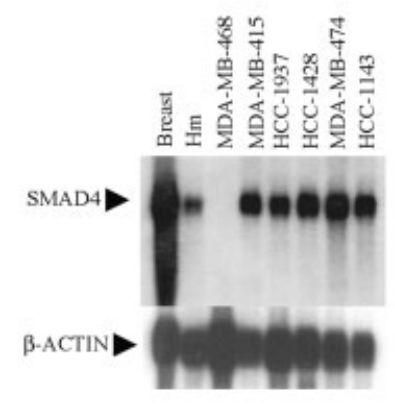

F)

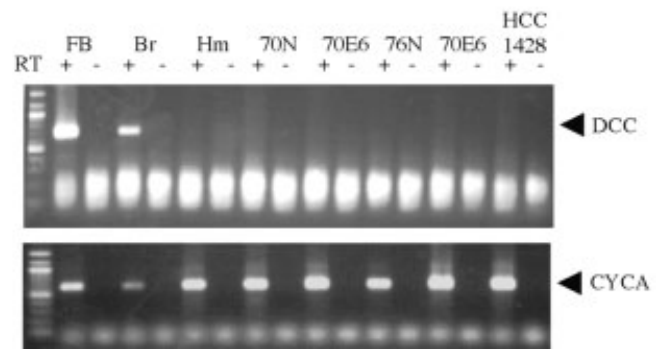

(D) Northern blot analysis of SMAD4 transcript demonstrates normal level in HCC-I428 cells compared to human breast tissue and other breast cancer cell lines (breast, whole RNA from human breast tissue; $\mathrm{Hm}$, human mammary epithelial cell culture; MDA-MB-468, negative control). (E) Western blot analysis of human cancer cell lines shows greatly attenuated SMAD4 protein in HCC-I428 cells (SW-480 and MDA-MB-468, negative controls). (F) RT-PCR does not amplify DCC cDNA from HCC-I428 or cultured human breast cells (FB, fetal brain cDNA template; $\mathrm{Br}$, human breast tissue; $\mathrm{Hm}$, human mammary epithelial cell culture).

ization of biallelic deletions of the $D C C$ locus in cancer demonstrated that these lesions were always intergenic, never limited to the $D C G$ gene itself. Indeed, some reported $D C G$ deletions include the BID-CHR18 locus (Hilgers et al.,
The relevance of $D C G$ to tumor suppression is a topic of much controversy. $D C C$ was first identified as a candidate tumor-suppressor gene by virtue of its position in a biallelic deletion in a colon tumor genome (Fearon et al., 1990). However, characteramplifies only a truncated product (C) Sequence analysis reveals a 9-bp deletion from exon I of SMAD4 of HCC-I428 (nucleotides deleted from HCC-I428 BL genome in box, deleted amino acids in boldface).

Figure 2. The HCC-I428 SMAD4 locus contains a 9-bp deletion sequence-specific DNA binding; $\mathrm{MH} 2$, mad homology 2 domain, involved in heteromerization and transactivation (Miyaki and Kuroki, 2003); amino and carboxy terminal residues indicated as $I$ and 552 , 
A)

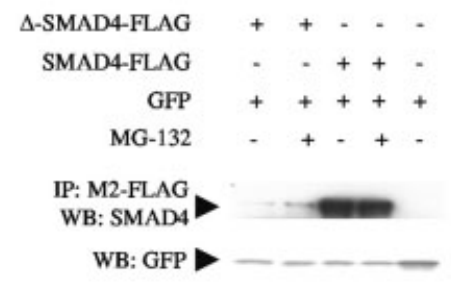

C)
B)
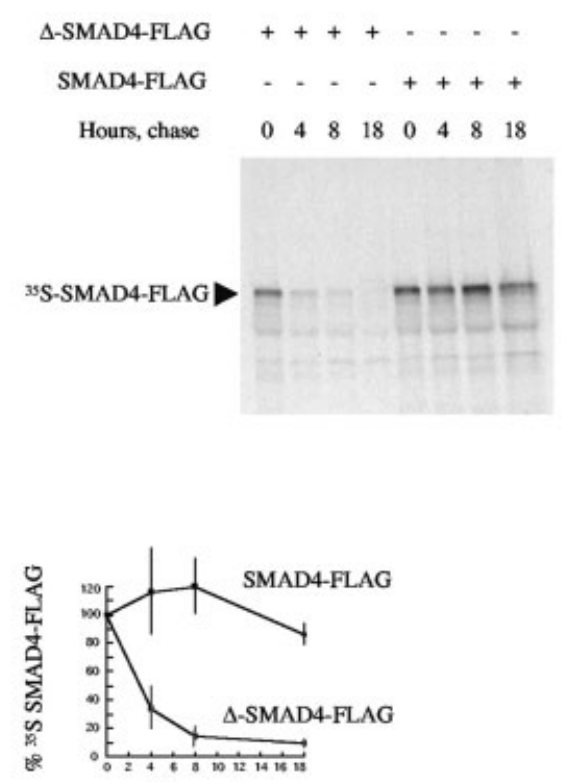

Hours, chase
Figure 3. The $\Delta(49-5 \mathrm{I})$ mutation accelerates $26 \mathrm{~S}$ proteasomemediated degradation. (A) Western blot analysis showing attenuated expression of $\Delta(49-51)-S M A D 4-F L A G$ versus SMAD4-FLAG in COS-I cells [ $\Delta$-SMAD4-FLAG, $\Delta(49-5$ I)-SMAD4-FLAG; MG- I 32, $50 \mu M$ MG132, $4 \mathrm{hr}$. Experiment was performed 3 times. (B) Pulse chase analysis demonstrating accelerated degradation of $\Delta(49-5 I)$-SMAD4-FLAG versus SMAD4-FLAG in COS-I cells [above, representative pulse chase experiment; below, vertical axis; ${ }^{35}$ S SMAD4-FLAG as percentage of

2000). No convincing somatic missense, nonsense, frameshift, or in-frame deletion mutations of the $D C G$ ORF have been reported in the literature (Cho et al., 1994; Miyake et al., 1994). Inherited mutation of $D C C$ also has been excluded as predisposing to hereditary colon cancer (Peltomaki et al., 1991). Finally, transgenic mice heterozygous for a $D C C$ knockout allele are not predisposed to colon cancer (Fazeli et al., 1997). Nonetheless, immunohistochemical studies indicated that DCC protein is absent in a subset of a variety of cancers including breast cancer (Koren et al., 2003). The presence of DCG protein has been shown to be a positive prognostic factor in stage II and stage III colorectal carcinoma (Shibata et al., 1996), and overexpression of Netrin-1, a DCG ligand, stimulates the formation of adenocarcinoma in $A p c$ mutant mice (Mazelin et al., 2004).

In contrast to $D C C, S M A D 4$ has been established as a canonical two-hit tumor-suppressor gene. SMAD4 has been shown to be biallelically deleted from a variety of pancreatic carcinoma cell line and signal at $0 \mathrm{hr}$; chase, average of 3 independent experiments; vertical bars, standard error at each time point; $\Delta$-SMAD4-FLAG, $\Delta(49-5 \mathrm{I})$ SMAD4-FLAG]. (C) Inhibition of the 26S proteasome rescues SMAD4 protein levels in HCC-1428 cells. Western blot analysis of endogenous $\mathrm{p} \triangle(49-5 \mathrm{I})-\mathrm{SMAD} 4$ in HCC-I428, T47D (unmutated SMAD4), MDAMB-428 cells (SMAD4 biallelicly deleted) (MG-132, $10 \mu \mathrm{M}$ MG-132, 24 hr; PS-34I, PS-34I, 24 hr).

xenograft genomes. Many of these deletions are intragenic, eliminating only the SMAD4 gene (Hahn et al., 1996b). Many somatic missense, nonsense, and frameshift mutations have been reported to occur in the SMAD4 ORF in pancreatic and colon carcinoma without concurrent amplification of normal the SMAD4 ORF sequence (IacobuzioDonahue et al., 2004). Inherited mutated alleles of SMAD4 are responsible for $50 \%$ of juvenile polyposis syndrome cases (Howe et al., 1998). SMAD4 protein has not been detected in polyps that develop in carriers of SMAD4 mutations, indicating loss of the normal SMAD4 allele (WoodfordRichens et al., 2001). Mice heterozygous for a SMAD4 knockout allele are predisposed to gastric polyposis, with loss of the normal SMAD4 allele in subsequent carcinomas ( $\mathrm{Xu}$ et al., 2000). The SMAD4 protein probably acts as a tumor suppressor through its signal transduction role in the TGFB pathway (Massague et al., 2000).

The novel deletions described in this report are true two-hit lesions. The normal paired genome 
Figure 4. Identification of chromosomal deletion of distal $18 q$ in HCC-1428. A metaphase with DAPI counterstain showing two centromeric signals of chromosome 18 (Orange) and chromosome 18 painting (Green). White arrow indicates the unbalanced chromosome 18 translocation with deletion of distal of $18 \mathrm{q}$

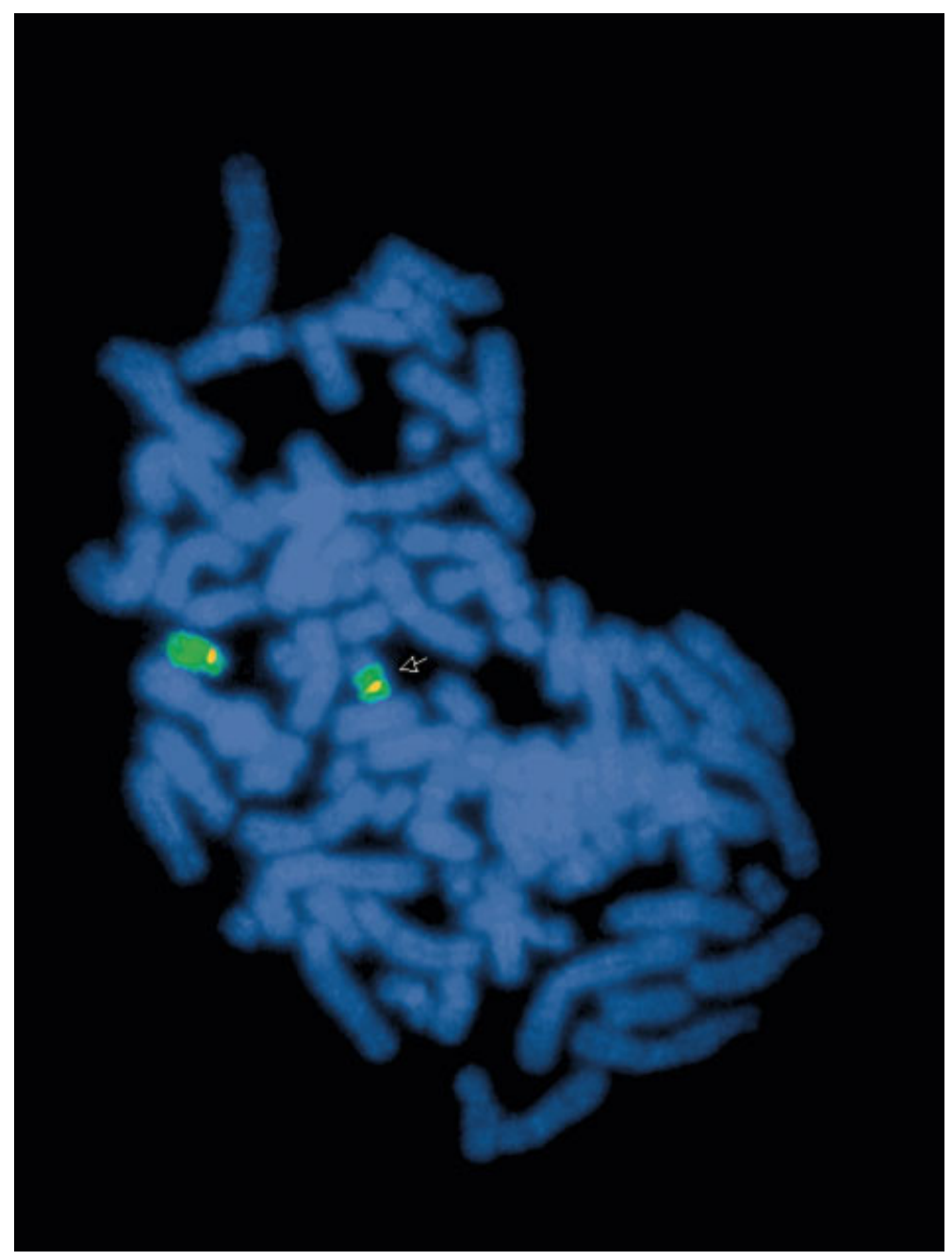

possesses two separate alleles at each deleted locus; both were lost en route to oncogenesis. Analysis of deletion maps from previous reports of chromosome arm $18 \mathrm{q}$ deletion in human cancer found complete (presumably biallelic) loss of $B I D$ CHR18 from other cancer cell lines and xenograft genomes. Specifically, studies of SMAD4 (Hahn et al., 1996a; Hilgers et al., 2000) and SMAD4 and $D C G$ (Thiagalingam et al., 1996) reported BIDCHR18 deletion from genomes of cancer cell lines and xenografts, although with the concomitant loss of the respective candidate tumor-suppressor genes. It therefore is possible that the phenotypic consequences of these large deletions are in part a result of the genetic information in BID-CHR18. Other studies have identified homozygous deletions centromeric to the SMAD4-BID-CHR18-DCC interval (Thiagalingam et al., 1996; Takei et al., 1998; Wilentz et al., 2000). Some of these deletions reduced the SMAD4 message by affecting a noncoding exon of SMAD4.
The putative relationship between $D C C$ expression in human breast epithelial cells with the BID-CHR18 locus is difficult to assess. Other investigations have shown the DCG protein to be breast in epithelia lining ducts and acini in vivo by immunohistochemical techniques (Koren et al., 2003). In our study, the $D C C$ transcript was detected in fetal brain and normal breast tissue, but not in three separate normal breast epithelial cell cultures or in HCC-1482 or other breast cancer cell lines (results not shown). $D C C$ transcription appears to be down-regulated in response to cell culture, independent of malignant transformation. This phenomenon has been observed by Thompson et al. (1993), who used Northern analysis to detect $D C G$ transcript in breast cancer tumors and MCF-7 xenograft cells but did not detect $D C G$ transcript in MCF-7 cells in culture or in the breast cancer cell lines MDAMB-231 and T-47D (Thompson et al., 1993). Therefore, we cannot rule out that deletion of 
BID-CHR18 may have affected the expression of $D C G$ in the context of the primary tumor, perhaps via elimination of a $D C C$ enhancer sequence. The definitive gene content of $B I D$ CHR18 is difficult to assess with current resources, and it does not contain any currently known genes.

The 9-bp $\triangle(49-51)$ SMAD4 mutation represents an additional two-hit lesion of the HCC1428 genome. No other in-frame 3-amino-aciddeletion mutations have been reported in SMAD4 in sporadic cancer or juvenile polyposis (JP), although one JP kindred has a 9-nucleotide deletion that eliminates amino acids 64-66 and adds a threonine (Woodford-Richens et al., 2000). The $\Delta(49-51)$ SMAD4 mutation is in the MH1 (Mad homology 1 domain) DNA-binding domain. Based on a comparison with the crystal structure of fellow SMAD protein family member SMAD3, amino acids 49-51 are not directly involved in DNA contact; however, SMAD4 missense mutations in the vicinity reduce DNA binding in vitro (Moren et al., 2000).

Notwithstanding the DNA-binding impairment conferred by MH1 cancer-specific mutations, Moren et al. (2003) and others have convincingly demonstrated that such lesions, specifically, L43S, G65V, R100T, and P130S, all inactivate the SMAD4 protein by enhancement of polyubiquitination and $26 \mathrm{~S}$ proteasome-mediated degradation (Xu and Attisano, 2000; Moren et al., 2003). Our own pulse chase analysis of exogenous $\Delta(49-51)$ SMAD4-FLAG protein and partial pharmacologic rescue of endogenous $\Delta(49-51)$ SMAD4 by inhibition of the $26 \mathrm{~S}$ proteasome confirmed that this mechanism is responsible for low levels of mutant protein. Other recent studies have demonstrated that the SMAD4 MH1 domain cancer mutants R100T, G65V, and L43S have increased susceptibility to ubiquitination and proteolysis mediated by E3 ubiquitin ligase complex $\mathrm{SCF}^{\text {skp2 }}$. Additional investigations are needed to confirm that $\Delta(49-51)$ SMAD4 also is targeted by the $\mathrm{SCF}^{\text {skp2 }}$ complex (Liang et al., 2004).

Partial pharmacologic rescue of endogenous $\Delta(49-51)-S M A D 4$ by inhibition of the $26 \mathrm{~S}$ proteasome confirm that increased degradation was responsible for the low level of SMAD4 protein, not loss of any information from 18q21.1, the deleted region, or elsewhere. This finding raises the possibility that TGFB signaling attenuated by SMAD4 mutation could be rescued in vitro or in vivo by pharmacological inhibition of the $26 \mathrm{~S}$ proteasome.

\section{REFERENCES}

Chen C, Gentles AJ, Jurka J, Karlin S. 2002. Genes, pseudogenes, and Alu sequence organization across human chromosomes 21 and 22. Proc Natl Acad Sci USA 99:2930-2935.

Chen H, Wang N, Huo Y, Sklar P, MacKinnon DF, Potash JB, McMahon FJ, Antonarakis SE, DePaulo JR, Jr., Ross CA, McInnis MG. 2003. Trapping and sequence analysis of 1138 putative exons from human chromosome 18. Mol Psychiatry 8: 619-623.

Cho KR, Oliner JD, Simons JW, Hedrick L, Fearon ER, Preisinger AC, Hedge P, Silverman GA, Vogelstein B. 1994. The DCC gene: structural analysis and mutations in colorectal carcinomas. Genomics 19:525-531.

den Dunnen JT, Antonarakis SE. 2000. Mutation nomenclature extensions and suggestions to describe complex mutations: a discussion. Hum Mutat 15(1):7-12.

Fazeli A, Dickinson SL, Hermiston ML, Tighe RV, Steen RG, Small CG, Stoeckli ET, Keino-Masu K, Masu M, Rayburn H, Simons J, Bronson RT, Gordon JI, Tessier-Lavigne M, Weinberg RA. 1997. Phenotype of mice lacking functional Deleted in colorectal cancer (Dcc) gene. Nature 386:796-804.

Fearon ER, Cho KR, Nigro JM, Kern SE, Simons JW, Ruppert JM, Hamilton SR, Preisinger AC, Thomas G, Kinzler KW, et al. 1990. Identification of a chromosome $18 \mathrm{q}$ gene that is altered in colorectal cancers. Science 247:49-56.

Feinberg AP, Vogelstein B. 1983. A technique for radiolabeling DNA restriction endonuclease fragments to high specific activity. Anal Biochem 132:6-13.

Gazdar AF, Kurvari V, Virmani A, Gollahon L, Sakaguchi M, Westerfield M, Kodagoda D, Stasny V, Cunningham HT, Wistuba II, Tomlinson G, Tonk V, Ashfaq R, Leitch AM, Minna JD, Shay JW. 1998. Characterization of paired tumor and non-tumor cell lines established from patients with breast cancer. Int J Cancer 78:766-774.

Hahn SA, Hoque AT, Moskaluk CA, da Costa LT, Schutte M, Rozenblum E, Seymour AB, Weinstein CL, Yeo CJ, Hruban RH, Kern SE. 1996a. Homozygous deletion map at 18q21.1 in pancreatic cancer. Cancer Res 56:490-494.

Hahn SA, Schutte M, Hoque AT, Moskaluk CA, da Costa LT, Rozenblum E, Weinstein CL, Fischer A, Yeo CJ, Hruban RH, Kern SE. 1996b. DPC4, a candidate tumor suppressor gene at human chromosome 18q21.1. Science 271:350-353.

Hilgers W, Song JJ, Haye M, Hruban RR, Kern SE, Fearon ER. 2000. Homozygous deletions inactivate DCC, but not MADH4/ DPC4/SMAD4, in a subset of pancreatic and biliary cancers. Genes Chromosomes Cancer 27:353-357.

Howe JR, Roth S, Ringold JC, Summers RW, Jarvinen HJ, Sistonen P, Tomlinson IP, Houlston RS, Bevan S, Mitros FA, Stone EM, Aaltonen LA. 1998. Mutations in the SMAD4/DPC4 gene in juvenile polyposis. Science 280:1086-1088.

Iacobuzio-Donahue CA, Song J, Parmiagiani G, Yeo CJ, Hruban RH, Kern SE. 2004. Missense mutations of MADH4: characterization of the mutational hot spot and functional consequences in human tumors. Clin Cancer Res 10:1597-604.

Kamb A, Gruis NA, Weaver-Feldhaus J, Liu Q, Harshman K, Tavtigian SV, Stockert E, Day RS 3rd, Johnson BE, Skolnick MH. 1994. A cell cycle regulator potentially involved in genesis of many tumor types. Science 264:436-440.

Koren R, Dekel Y, Sherman E, Weissman Y, Dreznik Z, Klein B, Gal R. 2003. The expression of DCC protein in female breast cancer. Breast Cancer Res Treat 80:215-220.

Lander ES, Linton LM, Birren B, Nusbaum C, Zody MC, Baldwin J, Devon K, Dewar K, Doyle M, FitzHugh W, et al. 2001. Initial sequencing and analysis of the human genome. Nature 409:860-921.

Lee WH, Bookstein R, Hong F, Young LJ, Shew JY, Lee EY. 1987. Human retinoblastoma susceptibility gene: cloning, identification, and sequence. Science 235:1394-1399.

Li J, Yen C, Liaw D, Podsypanina K, Bose S, Wang SI, Puc J, Miliaresis C, Rodgers L, McCombie R, Bigner SH, Giovanella BC, Ittmann M, Tycko B, Hibshoosh H, Wigler MH, Parsons R. 1997. PTEN, a putative protein tyrosine phosphatase gene mutated in human brain, breast, and prostate cancer. Science 275:1943-1947.

Li J, Simpson L, Takahashi M, Miliaresis C, Myers MP, Tonks N, Parsons R. 1998. The PTEN/MMAC1 tumor suppressor induces cell death that is rescued by the AKT/protein kinase B oncogene. Cancer Res 58:5667-5672.

Liang M, Liang YY, Wrighton K, Ungermannova D, Wang XP, Brunicardi FC, Liu X, Feng XH, Lin X. 2004. Ubiquitination and 
proteolysis of cancer-derived Smad4 mutants by SCFSkp2. Mol Cell Biol 24:7524-7537.

Lisitsyn N, Wigler M. 1993. Cloning the differences between two complex genomes. Science 259:946-951.

Liu CX, Musco S, Lisitsina NM, Forgacs E, Minna JD, Lisitsyn NA. 2000. LRP-DIT, a putative endocytic receptor gene, is frequently inactivated in non-small cell lung cancer cell lines. Cancer Res 60:1961-1967.

Massague J, Blain SW, Lo RS. 2000. TGFbeta signaling in growth control, cancer, and heritable disorders. Cell 103:295-309.

Mazelin L, Bernet A, Bonod-Bidaud C, Pays L, Arnaud S, Gespach C, Bredesen DE, Scoazec JY, Mehlen P. 2004. Netrin-1 controls colorectal tumorigenesis by regulating apoptosis. Nature 431:80-84.

Miyake S, Nagai K, Yoshino K, Oto M, Endo M, Yuasa Y. 1994. Point mutations and allelic deletion of tumor suppressor gene DCC in human esophageal squamous cell carcinomas and their relation to metastasis. Cancer Res 54:3007-3010.

Miyaki M, Kuroki T. 2003. Role of Smad4 (DPC4) inactivation in human cancer. Biochem Biophys Res Commun 306:799-804.

Moren A, Itoh S, Moustakas A, Dijke P, Heldin CH. 2000. Functional consequences of tumorigenic missense mutations in the amino-terminal domain of Smad4. Oncogene 19:4396-4404.

Moren A, Hellman U, Inada Y, Imamura T, Heldin CH, Moustakas A. 2003. Differential ubiquitination defines the functional status of the tumor suppressor Smad4. J Biol Chem 278:33571-33582.

Peltomaki P, Sistonen P, Mecklin JP, Pylkkanen L, Jarvinen H, Simons JW, Cho KR, Vogelstein B, de la Chapelle A. 1991. Evidence supporting exclusion of the DCC gene and a portion of chromosome $18 \mathrm{q}$ as the locus for susceptibility to hereditary nonpolyposis colorectal carcinoma in five kindreds. Cancer Res 51:4135-4140.

Ries LAG, Eisner MP, Kosary CL, Hankey BF, Miller BA, Clegg L, Mariotto A, Fay MP, Feuer EJ, Edwards BK, editors. 2003. SEER cancer statistics review, 1975-2000. Bethesda, MD: National Cancer Institute.

Sambrook J, Fritsch EF, Maniatis T. 1989. Molecular cloning. 2nd ed. Plainview, New York: Cold Spring Harbor Laboratory Press. p 7.19-7.22.

Schutte M, Rozenblum E, Moskaluk CA, Guan X, Hoque AT, Hahn SA, da Costa LT, de Jong PJ, Kern SE. 1995. An integrated high-resolution physical map of the DPC/BRCA2 region at chromosome 13q12. Cancer Res 55:4570-4574.

Schutte M, Hruban RH, Hedrick L, Cho KR, Nadasdy GM, Weinstein CL, Bova GS, Isaacs WB, Cairns P, Nawroz $\mathrm{H}$ and others. 1996. DPC4 gene in various tumor types. Cancer Res 56:25272530.

Shibata D, Reale MA, Lavin P, Silverman M, Fearon ER, Steele G, Jr., Jessup JM, Loda M, Summerhayes IC. 1996. The DCC protein and prognosis in colorectal cancer. N Engl J Med 335:17271732.

Struhl K. 2001. Short-term labeling of adherent cells with $35 \mathrm{~S}$ methionine. New York: John Wiley and Sons.

Takei K, Kohno T, Hamada K, Takita J, Noguchi M, Matsuno Y, Hirohashi S, Uezato H, Yokota J. 1998. A novel tumor suppressor locus on chromosome $18 \mathrm{q}$ involved in the development of human lung cancer. Cancer Res 58:3700-3705.

Thiagalingam S, Lengauer C, Leach FS, Schutte M, Hahn SA, Overhauser J, Willson JK, Markowitz S, Hamilton SR, Kern SE, Kinzler KW, Vogelstein B. 1996. Evaluation of candidate tumour suppressor genes on chromosome 18 in colorectal cancers. Nat Genet 13:343-346.

Thompson AM, Morris RG, Wallace M, Wyllie AH, Steel CM, Carter DC. 1993. Allele loss from 5q21 (APC/MCC) and 18q21 (DCC) and DCC mRNA expression in breast cancer. Br J Cancer 68(1):64-68

Tricarico C, Pinzani P, Bianchi S, Paglierani M, Distante V, Pazzagli M, Bustin SA, Orlando C. 2002. Quantitative real-time reverse transcription polymerase chain reaction: normalization to rRNA or single housekeeping genes is inappropriate for human tissue biopsies. Anal Biochem 309:293-300.

Waterston RH, Lindblad-Toh K, Birney E, Rogers J, Abril JF, Agarwal P, Agarwala R, Ainscough R, Alexandersson M, An P, et al. 2002. Initial sequencing and comparative analysis of the mouse genome. Nature 420:520-562.

Wazer DE, Liu XL, Chu Q, Gao Q, Band V. 1995. Immortalization of distinct human mammary epithelial cell types by human papilloma virus 16 E6 or E7. Proc Natl Acad Sci USA 92:3687-3691.

Wilentz RE, Su GH, Dai JL, Sparks AB, Argani P, Sohn TA, Yeo CJ, Kern SE, Hruban RH. 2000. Immunohistochemical labeling for dpc4 mirrors genetic status in pancreatic adenocarcinomas: a new marker of DPC4 inactivation. Am J Pathol 156(1):37-43.

Woodford-Richens K, Bevan S, Churchman M, Dowling B, Jones D, Norbury CG, Hodgson SV, Desai D, Neale K, Phillips RK, Young J, Leggett B, Dunlop M, Rozen P, Eng C, Markie D, Rodriguez-Bigas MA, Sheridan E, Iwama T, Eccles D, Smith GT, Kim JC, Kim KM, Sampson JR, Evans G, Tejpar S, Bodmer WF, Tomlinson IP, Houlston RS. 2000. Analysis of genetic and phenotypic heterogeneity in juvenile polyposis. Gut 46:656-660.

Woodford-Richens KL, Rowan AJ, Poulsom R, Bevan S, Salovaara R, Aaltonen LA, Houlston RS, Wright NA, Tomlinson IP. 2001. Comprehensive analysis of SMAD4 mutations and protein expression in juvenile polyposis: evidence for a distinct genetic pathway and polyp morphology in SMAD4 mutation carriers. Am J Pathol 159:1293-1300.

Wu KJ, Polack A, Dalla-Favera R. 1999. Coordinated regulation of iron-controlling genes, H-ferritin and IRP2, by c-MYC. Science 283:676-679.

Xie W, Mertens JC, Reiss DJ, Rimm DL, Camp RL, Haffty BG, Reiss M. 2002. Alterations of Smad signaling in human breast carcinoma are associated with poor outcome: a tissue microarray study. Cancer Res 62:497-505.

Xu J, Attisano L. 2000. Mutations in the tumor suppressors Smad2 and Smad4 inactivate transforming growth factor beta signaling by targeting Smads to the ubiquitin-proteasome pathway. Proc Natl Acad Sci USA 97:4820-4825.

Xu X, Brodie SG, Yang X, Im YH, Parks WT, Chen L, Zhou YX, Weinstein M, Kim SJ, Deng CX. 2000. Haploid loss of the tumor suppressor Smad4/Dpc4 initiates gastric polyposis and cancer in mice. Oncogene 19:1868-1874. 